\title{
ASSESSMENT OF THE EFFICIENCY OF BIOLOGICAL TREATMENT OF GASES FROM MUNICIPAL WASTE PROCESSING
}

\author{
OCENA EFEKTYWNOŚCI BIOLOGICZNEGO OCZYSZCZANIA GAZÓW \\ POPROCESOWYCH Z PRZETWARZANIA ODPADÓW KOMUNALNYCH
}

\begin{abstract}
The objective of the study is research on a biofilter existing at a mechanical-biological waste treatment plant in Radom. The paper presents results of research on the filling of the analysed biofilter (moisture, organic matter content, nutrient content, $\mathrm{pH}$, grain size composition, and equivalent diameter), process gases (temperature, humidity and $\mathrm{pH}$, concentrations of the main pollutants - ammonia, hydrogen sulphide, volatile organic compounds, acetic acid, ethanol) and operational parameters (flow rate, height of the biofilter layer, surface load, gas residence time in the filter bed). Irregularities were observed related to biofiltration efficiency, particularly resulting from improperly selected filling material and improper biofilter operation. The technological research permitted the identification of problems and determination of the requirement of performing necessary operational changes. Further works will involve the design, manufacture, and installation of an integrated biofilter with two-stage gas purification process (a classic biofilter and a semi-permeable membrane).
\end{abstract}

Keywords: biofiltration, filling material, gas treatment efficiency, municipal waste

\section{Introduction}

Process gases from municipal waste treatment contain numerous organic (volatile fatty acids, aldehydes, ketones, alcohols) and inorganic compounds (hydrogen sulphide, ammonia) [1]. They are tedious for the surroundings due to their intensive unpleasant smell. They can also negatively affect human health and the environment. Their emission to the atmosphere causes progressing deterioration of the atmospheric air quality, and constitutes a serious hazard for health and life [2]. The origin and expansion of smell in mechanical-biological treatment (MBT) process of municipal solid waste (MSW) particularly depends on waste composition, applied technology, including the type of the conducted process in the biological part (aerobic/anaerobic), degree of air-tightening, way of managing the process in the installation, and possibility of capture and purification of emitted process gases. The composition of gases from MBT plants is related to the

\footnotetext{
${ }^{1}$ Faculty of Building Services, Hydro and Environmental Engineering, Warsaw University of Technology, ul. Nowowiejska 20, 00-653 Warszawa, Poland, phone +48 2223453 05, fax +48 22 625-4305

*Corresponding author: piotr.manczarski@pw.edu.pl
} 
processing stage (mechanical/biological part) and to the phase of biochemical process $[3,4]$.

Possibilities for limiting the smell-related tediousness of MBT plants particularly include the application of biological treatment methods (BTM) of emitted gases. They use the natural potential of microorganisms to decompose contaminants. In comparison to other methods, they have the advantage of removing various impurities (pollutants), even if they occur in one mixture of gases [5].

A popular BTM of gases from biological treatment of waste is biofiltration, due to among others higher diversity of microorganisms occurring in the filling material in comparison to other biological methods, possibility of removal of compounds weakly soluble in water from gases, and usually simpler and cheaper exploitation [5]. Biofilters can be applied for removal of both organic compounds (alcohols, ketones, alkanes, benzene derivatives, chlorinated hydrocarbons, aliphatic and aromatic contaminants, aldehydes, organic acids, amines, glycols, ethyl acetate, butyl acetate, isobutanol, phenol) and inorganic compounds (hydrogen sulphide, sulphur dioxide, methyl sulphide, ammonia, nitrogen oxide) [6,7]. During the flow of gases through the layer, contaminants are absorbed and decomposed. The common application of biofilters is related to their simplicity, low cost, possibility of removal of an increasing range of compounds, and lack of tedious waste generation.

The efficiency of biofiltration, depending on the type of treated gases and type of installation, usually varies from 80 to $100 \%$, although also lower efficiencies can be recorded, at a level of 50-80\% [8]. The efficiency of biofiltration largely depends on the operational parameters of the MBT plant, and particularly on the degree of surface load, height of the filling layer, gas residence time in the filter bed, and flow resistance. A very important factor determining good effects of the biofiltration process is also proper selection of the filling material [6]. The efficiency of gas treatment largely depends on parameters of the filling such as: content of organic and nutrient substances, grain size composition (equivalent diameter), moisture and water retention capacity, $\mathrm{pH}$, and temperature. The parameters of gases directed to biological treatment in a biofilter, namely moisture, temperature, type and amount of contaminants, are of importance for the effectiveness of their purification.

Surface load of a biofilter is the acceptable gas volume flowing through a unitary surface area in a time unit, also expressed as the rate of gas flow through the filling layer. According to [9], the applied rate values are within a range of $0.0056-0.14 \mathrm{~m} \cdot \mathrm{s}^{-1}$, equivalent to surface load of $20-500 \mathrm{~m}^{3} /\left(\mathrm{m}^{2} \cdot \mathrm{h}\right)$. Other sources indicate recommended gas flow rates at a level from 0.01 to $0.1 \mathrm{~m} / \mathrm{s}$. Pursuant to guidelines of VDI 3477, the surface load should be in a range of $45-150 \mathrm{~m}^{3} /\left(\mathrm{m}^{2} \cdot \mathrm{h}\right)[10]$.

The height of the filling layer in functioning biofilters usually varies from 0.5 to $1.6 \mathrm{~m}$. The minimum thickness should ensure constant gas flow, sufficiently long time of gas residence in the filter bed, and prevent the occurrence of deposit perforation. The gas residence time in the filter bed usually varies from $6 \mathrm{~s}$ to $720 \mathrm{~s}$ [10]. [11] recommends that for compost biofilters it should amount to $30 \mathrm{~s}$, and for soil biofilters - minimum $1 \mathrm{~min}$.

Resistance of gas flow through the filling layer in functioning biofilters usually varied from 1.2 to $12.5 \mathrm{hPa}$ [10]. It depends on the type of the filling material, its moisture, and gas flow rate (surface load). For a compost biofilter with bark, at a surface load of $300 \mathrm{~m}^{3} /\left(\mathrm{m}^{2} \cdot \mathrm{h}\right)$ and height of the filling layer of $1 \mathrm{~m}$, a decrease in pressure did not exceed $4.5 \mathrm{hPa}$ [12]. Biofilters operated with surface load in a range of $62.4-100.5 \mathrm{~m}^{3} /\left(\mathrm{m}^{2} \cdot \mathrm{h}\right)$, filled 
with a mix of stumpwood chips and pine bark or stumpwood chips with pine bark and green waste compost with moisture from 42.7 to $66.3 \%$, were characterised by flow resistance in a range of 3.8-5.4 $\mathrm{hPa}$ [13]. According to German findings [10], flow resistance is in a range of 6-12 $\mathrm{hPa}$ in biofilters with filling in the form of compost from waste, with moisture of 50-65 \%, functioning with surface load of up to $90 \mathrm{~m}^{3} /\left(\mathrm{m}^{2} \cdot \mathrm{h}\right)$.

The presence of moisture in the filling layer favours the process of microbiological oxidation. It is the basic condition providing for optimum activity of microorganisms [14]. It largely determines the efficiency of gas treatment. The moisture of the filling and height of its layer are the most important parameters for maintaining proper functioning of a biofilter. More than $50 \%$ of operation problems are related to the moisture of the filter bed. According to VDI 2004, moisture should be maintained in a range of 30-60\%. The paper [15] specifies the optimum content of water in compost filling of biofilters from 20 to $40 \%$, and for soil biofilters $10-20 \%$. Moisture of $10-20 \%$ for soil biofilters is confirmed [16], and for compost and peat biofilters it is specified to vary from 30 to $80 \%$. In general, the value of recommended moisture in biofilters is $40-60 \%$ of the water-holding capacity of the media, depending on the filtering medium used [11]. Excessive saturation with water of the filtering medium contributed to the occurrence of anaerobic conditions and stagnation zones with limited [8], an increase in flow resistance and energetic requirements, and a decrease in biofiltration efficiency. Insufficient water content causes cracking of the medium, and a decrease in microbiological activity [16], also contributing to a reduction of gas purification efficiency.

Proper content of organic matter in the filtering medium is also necessary for maintaining the proper amount and activity of microorganisms. According to [17], the content of organic material in the biofilter medium should amount to a minimum of $55 \%$, and the ration of elements $\mathrm{C}: \mathrm{N}: \mathrm{P}$ - 100:5:1. Pursuant to [10], the proportions between carbon, nitrogen, and phosphorus should be maintained at a level of 200:10:1.

The filtering medium should be characterised by grain composition allowing for the equivalent diameter of its grains to be larger than $4 \mathrm{~mm}$ [16]. $\mathrm{pH}$ of the filling material should be within a range of 6-9 [6,16] (a decrease below such values frequently results in a decrease in biofiltration efficiency). Temperature in the filtering medium is related to the activity of microorganisms and temperature of the treated gas [6]. According to [14], optimum temperature values amount to $25-40{ }^{\circ} \mathrm{C}$, and pursuant to [15], they should not exceed $50{ }^{\circ} \mathrm{C}$. The adopted optimum range is $25-40{ }^{\circ} \mathrm{C}$ [6]. According to [18], the optimum temperature of the process amounts to $37{ }^{\circ} \mathrm{C}$. [16] provide examples of operation of biofilters at a filtering medium temperature below $10{ }^{\circ} \mathrm{C}$.

Before the biofiltration process, gases should be moistened to the state of saturation [6], and their temperature should not exceed $60{ }^{\circ} \mathrm{C}$. Its recommended range varies from the minimum above water freezing temperature and maximum of $40{ }^{\circ} \mathrm{C}$ [14].

\section{Objective and scope of the study}

The objective of the study is research on a biofilter existing in a MBT plant, taking into consideration its filling material (filter bed), process gases (raw and treated), operational parameters, and efficiency. The research results will provide the basis for the development of a new integrated biofilter with two-stage gas purification process to optimise the operating parameters and to achieve a significant reduction of emissions at a low cost for biofiltration of various processing gases. 


\section{Study object}

The study object is a biofilter located in the premises of a MBT plant in Radom (Poland). It is an open surface biofilter, with dimensions of $13.25 \mathrm{~m}$ x $29.89 \mathrm{~m}$ (biologically active area: $396 \mathrm{~m}^{2}$ ). Process gases discharged from the preliminary processing hall and hall of biological treatment of MSW are directed to a scrubber, and then to the analysed biofilter. It offers a possibility of purification a maximum $45000 \mathrm{~m}^{3} \cdot \mathrm{h}^{-1}$ gases.

The filling material is composed of: wood chips, edgings (chopped spruce wood), bark, fibrous peat, and heather. Areas covered with branches, moss, and wood chips were observed on the surface (Fig. 1). The height of the biofilter layer varies from 0.5 to $0.7 \mathrm{~m}$. This is due to the unequal settling of the filling layer and the lack of care treatments (including supplementing of the filling material) carried out by the operator.

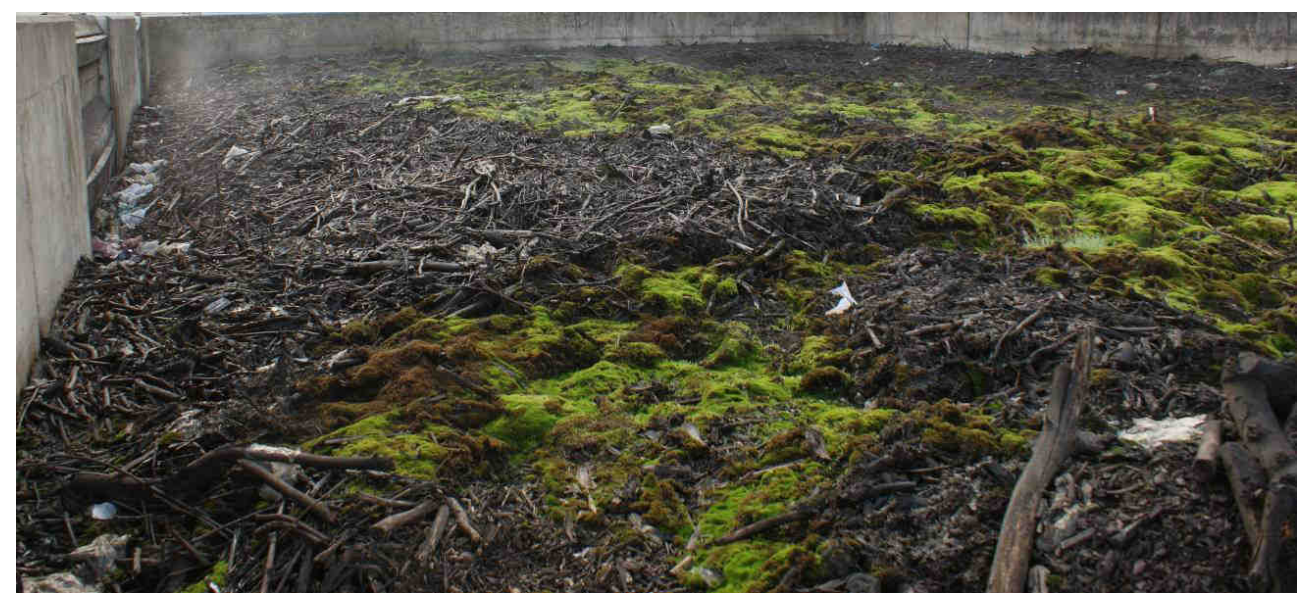

Fig. 1. View of the surface of the analysed biofilter

\section{Scope of the study}

Research conducted in the scope of this study, constituting its first stage, included:

1. analysis of the biofilter bed: moisture, organic matter content, nutrient content, $\mathrm{pH}$, grain size distribution, and equivalent diameter;

2. analysis of gases before and after purification: temperature, humidity and $\mathrm{pH}$, concentrations of the main contaminants (hydrogen sulphide, volatile organic compounds - VOC, acetic acid, ethanol);

3. assessment of the operating parameters: flow rate, height of the biofilter layer, surface load, gas residence time in the filter bed.

\section{Study methods}

The research was conducted based on the methodology presented in Table 1.

Samples from the surface of the biofilter (from a surface source) were collected with the application of a shield eliminating the effect of external conditions. For this purpose, a glass funnel set on the surface of the filling layer inside a metal or plastic cover was used. 
A pipe used to collect gases or a thermoanemometer probe was input into the screened funnel.

Table 1

Study methods

\begin{tabular}{|c|c|c|}
\hline Indicator & Study method & Comments \\
\hline $\begin{array}{l}\text { Determination of } \mathrm{pH} \text { of the } \\
\text { filter bed }\end{array}$ & [19] & $\begin{array}{c}\text { Determination of } \mathrm{pH} \text { for an air-dry } \\
\text { sample, the ratio of sample: } \\
\text { water }=1: 10\end{array}$ \\
\hline $\begin{array}{c}\text { Determination of total } \\
\text { moisture of the filter bed }\end{array}$ & {$[20]$} & ( \\
\hline $\begin{array}{l}\text { Determination of the } \\
\text { content of organic } \\
\text { substances, organic carbon, } \\
\text { nitrogen, phosphorus in the } \\
\text { filter bed }\end{array}$ & {$[21]$} & - \\
\hline $\begin{array}{l}\text { Grain size composition of } \\
\text { the filling material }\end{array}$ & & $\begin{array}{c}\text { Sieves were used with openings: } \\
0.071 ; 0.1 ; 0.25 ; 0.5 ; 1.0 ; 2.0 \\
10.0 ; 25.0 \mathrm{~mm}\end{array}$ \\
\hline $\begin{array}{l}\text { Determination of the } \\
\text { content of organic } \\
\text { substances, organic carbon, } \\
\text { nitrogen, phosphorus in the } \\
\text { filter bed }\end{array}$ & {$[22]$} & - \\
\hline $\begin{array}{l}\text { Temperature in the filter } \\
\text { bed }\end{array}$ & $\begin{array}{c}\text { Measurement by means of a temperature sensor } \\
\text { TP-03 with an electronic meter by Czaki } \\
\text { Termo-Product, type EMT-06 }\end{array}$ & Limit of detection: $0.1^{\circ} \mathrm{C}$ \\
\hline $\begin{array}{l}\text { Content of ammonia, } \\
\text { hydrogen sulphide, VOC in } \\
\text { process gases (before and } \\
\text { after purification) }\end{array}$ & $\begin{array}{c}\text { Measurement by means of a multi-gas detector } \\
\text { MultiRAE (Rae Systems) }\end{array}$ & $\begin{array}{l}\text { Multi-gas detector with sensors } \\
\text { based on various measurement } \\
\text { techniques (electrochemical and } \\
\text { catalytic sensors, in infrared, } \\
\text { photoionization, sensor PID etc.). } \\
\text { Limits of detection: } \\
\text { ammonia: } 1 \text { ppm } \\
\text { hydrogen sulphide: } 0.1 \mathrm{ppm} \\
\text { VOC: } 1 \mathrm{ppb} \\
\end{array}$ \\
\hline $\begin{array}{l}\text { Content of acetate acid and } \\
\text { ethanol in process gases } \\
\text { (before and after } \\
\text { purification) }\end{array}$ & $\begin{array}{c}\text { Measurement by means of indicator tubes (Rae } \\
\text { Systems) }\end{array}$ & $\begin{array}{l}\text { Colorimetric method - a gas } \\
\text { sample is pulled through a glass } \\
\text { tube containing a reagent, and } \\
\text { a reaction between the gas and } \\
\text { solid reagent forms a colour that is } \\
\text { related to the concentration of the } \\
\text { gas. } \\
\text { Limits of detection: } \\
\text { acetate acid: } 0.25 \mathrm{ppm} \\
\text { ethanol: } 0.01 \%\end{array}$ \\
\hline $\begin{array}{l}\text { Temperature, humidity of } \\
\text { gases (before and after } \\
\text { purification) }\end{array}$ & $\begin{array}{c}\text { Measurement by means of } \\
\text { a thermoanemometre TA440 (Airflow } \\
\text { Instruments) }\end{array}$ & $\begin{array}{l}\text { Limits of detection: } \\
\text { temperature: } 0.1^{\circ} \mathrm{C} \\
\text { humidity: } 0.1 \%\end{array}$ \\
\hline
\end{tabular}

\section{Study results}

Tables 2 and 3 present study results concerning the filling materials in the analysed biofilter, process gases, and operational parameters. 
Collective results of analyses of material filling the analysed biofilter

\begin{tabular}{|c|c|c|c|c|}
\hline Physical-chemical properties & Units & Average value \pm SD & Range & Number of samples \\
\hline Moisture content & {$[\%]$} & $77.2 \pm 0.3$ & $76.8-77.4$ & 9 \\
\hline $\mathrm{pH}$ & {$[-]$} & $5.55 \pm 0.17$ & $5.41-5.80$ & 9 \\
\hline Temperature & {$\left[{ }^{\circ} \mathrm{C}\right]$} & $24.0 \pm 6.0$ & $15.5-31.5$ & 15 \\
\hline Organic matter content & {$[\%$ d.m.] } & $91.3 \pm 1.5$ & $90.17-93.31$ & 9 \\
\hline Organic carbon & {$[\%$ d.m.] } & $44.8 \pm 1.5$ & $43.24-46.37$ & 9 \\
\hline Organic nitrogen & {$[\%$ d.m.] } & $2.50 \pm 0.23$ & $2.30-2.80$ & 9 \\
\hline Organic phosphorus & {$\left[\% \mathrm{P}_{2} \mathrm{O}_{5}\right.$ d.m.] } & $0.21 \pm 0.02$ & $0.19-0.23$ & 9 \\
\hline C:N:P & {$[-]$} & $200: 11: 1$ & - & - \\
\hline Equivalent diameter & {$[\mathrm{mm}]$} & $12.2 \pm 1.5$ & $10.3-13.7$ & 9 \\
\hline
\end{tabular}

Collective study results concerning process gases and operational parameters of the analysed biofilter

\begin{tabular}{|c|c|c|c|c|}
\hline Indicator & Units & $\begin{array}{c}\text { Average value } \\
\pm S D\end{array}$ & Range & $\begin{array}{c}\text { Number of } \\
\text { samples }\end{array}$ \\
\hline \multicolumn{5}{|c|}{ Operational parameters of the biofilter } \\
\hline Flow rate & {$\left[\mathrm{m}^{3} \cdot \mathrm{h}^{-1}\right]$} & $33980 \pm 2595$ & $\begin{array}{l}30200-37200 \\
\text { (operator data) } \\
\end{array}$ & 5 \\
\hline Height of the biofilter layer & [m] & $0.6 \pm 0.1$ & $0.5-0.7$ & 15 \\
\hline Biofilter active area & {$\left[\mathrm{m}^{2}\right]$} & \multicolumn{2}{|c|}{$\begin{array}{c}396 \\
\text { (operator data) } \\
\end{array}$} & - \\
\hline Surface load & {$\left[\mathrm{m}^{3} /\left(\mathrm{m}^{2} \cdot \mathrm{h}\right)\right]$} & $85.6 \pm 6.7$ & $\begin{array}{c}76-94 \\
\text { (calculated } \\
\text { values) }\end{array}$ & 5 \\
\hline Gas residence time in the filter bed & {$[\mathrm{s}]$} & $25.6 \pm 1.5$ & $\begin{array}{c}24-28 \\
\text { (calculated } \\
\text { values) } \\
\end{array}$ & 5 \\
\hline \multicolumn{5}{|c|}{ Raw gases } \\
\hline Humidity & {$[\%]$} & $100 \pm 0$ & 100 & 15 \\
\hline Temperature & {$\left[{ }^{\circ} \mathrm{C}\right]$} & $27.8 \pm 2.9$ & $25-33$ & 15 \\
\hline $\mathrm{pH}$ & {$[-]$} & $7.12 \pm 0.32$ & $\begin{array}{c}6.72-7.50 \\
\text { (operator data) }\end{array}$ & 5 \\
\hline \multicolumn{5}{|c|}{ Purified gases } \\
\hline $\begin{array}{l}\text { Removal efficiency of hydrogen } \\
\text { sulphide }\end{array}$ & {$[\%]$} & $77.4 \pm 29.6$ & $20-100$ & 9 \\
\hline Removal efficiency of VOC & {$[\%]$} & $53.1 \pm 19.7$ & $14-84$ & 13 \\
\hline Removal efficiency of acetic acid & {$[\%]$} & $100 \pm 0$ & 100 & 9 \\
\hline Removal efficiency of ethanol & {$[\%]$} & $100 \pm 0$ & 100 & 9 \\
\hline
\end{tabular}

\section{Analysis of results and discussion}

Five measurement series were carried out - between 7th of February and 24th of April 2017. The tested biofilter is the open installation (without the chimney), so samples of gases were taken from its surface and were collected with the application of a shield eliminating the effect of external conditions (described in Study methods).

The material filling the biofilter was sampled during three measurement series (between 7th of February and 24th of April 2017), each time from three places of the installation. The sampling points are presented in Figure 2 as I, II, III. 


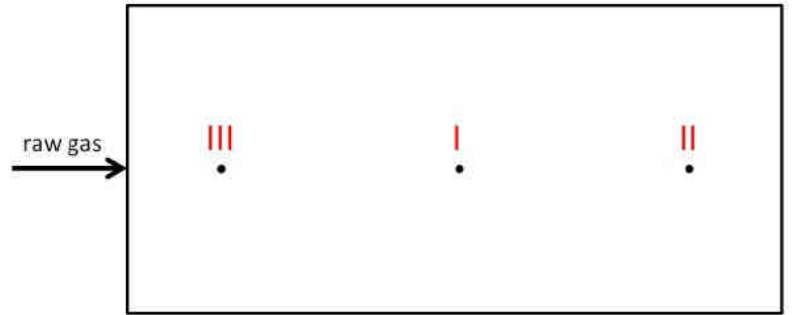

Fig. 2. Points of sampling of the filling material and purified process gases

The obtained results show that material filling the analysed biofilter is characterised by very high content of total organic substance and organic carbon - from 90.4 to $93.3 \%$ and from 43.2 to $46.4 \%$, respectively (Table 2). No considerable differences were observed in the duration of the research cycle (during the measurement series - 7th of February, 17th of March and 24th of April), irrespective of the place of sampling. The ratio C:N:P (200:11:1) is in accordance with values recommended in the literature [10].

Equivalent diameter of the filling varied from 12.5 to $13.7 \mathrm{~mm}$ (Table 2), corresponding with values indicated as proper ones - larger than $4 \mathrm{~mm}$ [17]. Large pieces of the branches (Fig. 3) cover the fragments of the filter only on the surface (they constitute only a thin layer on the surface of the filter bed).

The obtained results show very high moisture of the applied material filling the analysed biofilter, maintained at a constant level (approximately $77 \%$ ) during the research cycle, irrespective of the place of sampling (Table 2). The level of moisture determined based on the conducted research exceeds recommended values $[10,14,16]$ (although they depend on the type of filling material), what creates the hazard of occurrence of anaerobic zones.

The $\mathrm{pH}$ of the filter bed varied from 5.41 to 5.80 (Table 2). The values are below the recommended level $[6,16]$.

The height of the filter bed is variable, and ranges from 0.5 to $0.7 \mathrm{~m}$ (Table 2). Values at this level are indicated as minimum values for efficient operation of the biofilter unit [10]. However, the diversified height of the filling layer, caused by improper operation, will affect the distribution of the air flow because the resistance is different and more air will flow though the spots with less height, contributing to smaller efficiency.

Temperature inside the filter bed was maintained in a range from 15.5 to $31.5{ }^{\circ} \mathrm{C}$ (Table 2), and largely depended on the temperature of the surroundings.

The analysed biofilter is a surface open biofilter operating with proper surface load varying from 76 to $94 \mathrm{~m}^{3} /\left(\mathrm{m}^{2} \cdot \mathrm{h}\right)$. It is, however, characterised by short time of residence of treated gases in the filter bed - from 23 to $28 \mathrm{~s}$ (Table 2) - some literature sources indicate the values as the bottom threshold of the recommended level [11] - it is related to the insufficient height of the filter bed.

Process gases were sampled during five measurement series. Raw gases were sampled in the place of their introduction into the biofilter (Fig. 3), and purified gases - each time from three places of installation (Fig. 2). 


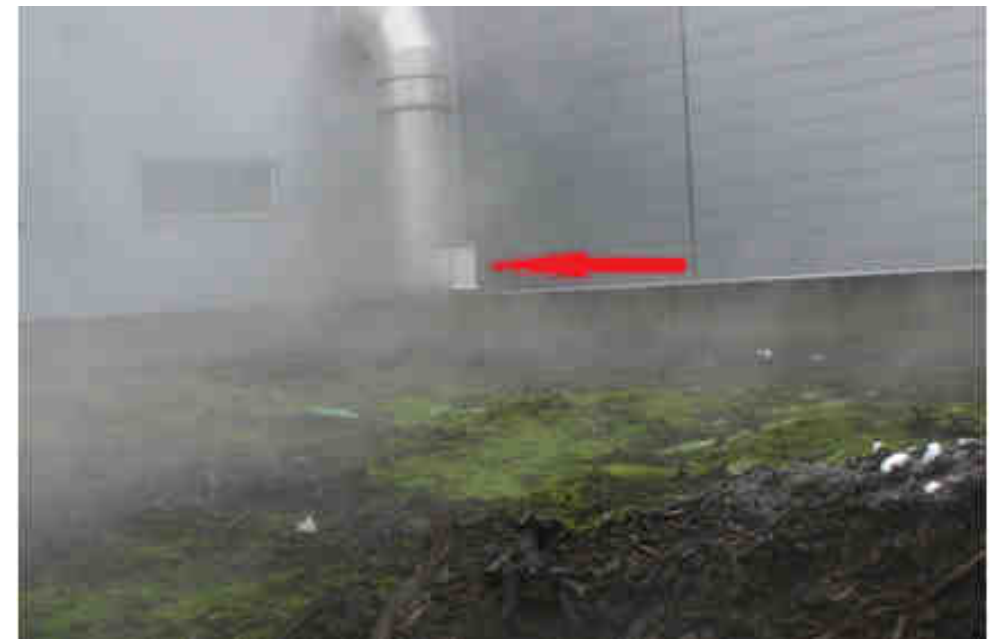

Fig. 3. Supply of process gases to the analysed biofilter; indication of the sampling places of raw gases

The basic parameters of raw gases (humidity, temperature, content of main contaminants) are correct, and do not disqualify them from purification with the application of biological methods.

Irregularities were recorded, however, related to the efficiency of biofiltration, particularly resulting from improperly selected filling material and improper operation of the biofilter. In reference to contaminants contained in raw gases in small amounts (ethanol, acetic acid), $100 \%$ purification efficiency was determined (Table 3). However, the high water solubility of these compounds also contributes to purification efficiency. In addition, the detection threshold of the measuring method of ethanol and acetic acid should be considered (Table 1). In the case of contaminants occurring in higher concentrations VOC, the efficiency was considerably lower, and adopted variable values - from 14 to $84 \%$ (Table 3). Moreover, in different places of installation, secondary contamination periodically occurred (an increase in VOC emission, which means an increase in VOC concentration in gases after biofilter probably caused by the development of anaerobic processes in the filter bed or by the decomposition of unstable filling material). A change in the operation conditions caused no substantial changes in the efficiency of removal of the main contaminant, namely VOC.

The removal of hydrogen sulphide with the application of the analysed filter was also maintained at a variable level - from 20 to $100 \%$ (Table 3) - in spite of the concentration at the level of $0.4-0.5 \mathrm{ppm}$ in raw gases - detected only periodically. Also in this case, secondary contamination was observed, manifested by an increase in hydrogen sulphide emissions (after biofilter), which was most probably caused by the appearance of anaerobic zones in the filling layer.

Conducted study points out that increased concentrations of VOC and hydrogen sulphide in gases after biofiltration result from improper operation of the installation, related to the maintenance of excessive moisture of the filter bed. This results in the aerobic-anaerobic character of processes occurring inside the layer.

Ammonia was not detected either in raw or purified gases. 


\section{Summary and conclusions}

The study shows that the analysed biofilter is characterised by correct surface load, and the treated gases - by correct basic parameters permitting their purification by means of biotechnological methods.

The filter filling constituted material with favourable content of organic and nutrient substances, however with excessive water-holding capacity, which makes it difficult to maintain humidity at the proper level. The variable results concerning biofiltration efficiency reveal the non-homogenous character of gas flow through the filter bed and presence of inactive zones in the filter bed. Irregularities related to biofiltration efficiency particularly result from improperly selected filling material and improper operation of the biofilter. They result from the maintenance of excessive moisture in the filter bed, leading to the aerobic-anaerobic character of processes occurring inside it. However, not only excessive filling humidity is the reason for the decrease of biofiltration efficiency. It is also necessary to take care of treatments consisting in maintaining a constant height of the filling layer and the correct surface (without moss, branches and plants).

Technological research suggests the requirement of performing necessary operational changes in the scope of:

1. applied filling materials - exchange of the filter bed,

2. moisture of the filter bed - operation permitting the maintenance of moisture in a range of $20-60 \%$,

3. $\mathrm{pH}$ of the filter bed - selection of the proper filling material and operation permitting the maintenance of $\mathrm{pH}$ in a range of 6-9,

4. height of the filling layer - control of the thickness of the layer, and its maintenance at a constant level of approximately $1 \mathrm{~m}$ which should be persistent over the entire biofilter surface,

5. time of residence of gases in the filter bed - extension of the residence time through the adjustment and control of the thickness of the filling material layer.

Further works will involve the design, manufacture, and installation of an integrated biofilter prototype, research on the integrated biofilter (semi-technical scale) - concept verification and modification of the biofilter existing at the mechanical-biological waste treatment plant (which was tested in this work) according to the guidelines obtained at previous stages. The integrated biofilter is intended to conduct a two-stage gas purification process. Stage I will be a classic biofilter, and stage II - purification with a semi-permeable membrane.

The following further results are expected: the membrane covering the biofilter (the second stage of purification) will permit better control of the processes; the membrane as a specific type of biofilter cover will help maintain proper moisture in the biofilter layer; the membrane will also be important in the purification processes (sorption and biodegradation); the membrane will minimise the microorganism emissions from the biofilter.

\section{Acknowledgements}

The research was financed from the Intelligent Development operational program, action 4.1 Research and development works, sub-action 4.1.2 Regional science and research agendas, intermediate institution: National Center for Research and Development.

Project Contract No POIR.04.01.02-00-0019/16. url: https://biozin.wordpress.com/. 


\section{References}

[1] Scaglia B, Orzi V, Artola A, Font X, Davoli E, Sanchez A, et al. Bioresour Technol. 2011;102(7):4638-45. DOI: 10.1016/j.biortech.2011.01.016.

[2] Ren Y, Qu Z, Du Y, Xu R, Ma D, Yang G, et al. Environ Pollut. 2017;230:849-61. DOI: 10.1016/j.envpol.2017.06.049.

[3] Fang J, Zhang H, Yang N, Shao L, He P. Gaseous pollutants emitted from a mechanical biological treatment plant for municipal solid waste: Odor assessment and photochemical reactivity. J Air Waste Manage Assoc. 2013;63:11:1287-97. DOI: 10.1080/10962247.2013.822439.

[4] Colón J, Alvarez C, Vinot M, Lafuente FJ, Ponsá S, Sánchez A, et al. Characterization of odorous compounds and odor load in indoor air of modern complex MBT facilities. Chem Eng J. 2017;313:1311-9. DOI: 10.1016/j.cej.2016.11.026.

[5] Barbusinski K, Kalemba K, Kasperczyk D, Urbaniec K, Kozik V. J Cleaner Product. 2017;152:223-41. DOI: 10.1016/j.jclepro.2017.03.093.

[6] Gałwa-Widera M, Kwarciak-Kozłowska A, Bień J. Reduction of odour nuisance of industrial plants biofiltering in composting plants. J Ecol Eng. 2018;19(5):135-43. DOI: 10.12911/22998993/89821.

[7] Wani AH, Branion RMR, Lau AK. Biofiltration. J Environ Sci Health. 1997;32:2027-55. DOI: $10.1080 / 10934529709376664$.

[8] Khan F, Ghoshal A. Removal of volatile organic compounds from polluted air. J Loss Prev Process Ind. 2000;(13):527-45. DOI: 10.1016/S0950-4230(00)00007-3.

[9] Tiwari A, Alam T, Kumar A, Shukla A. Control of odour, volatile organic compounds (VOCs) \& toxic gases through biofiltration - An overview. Int $J$ Tech Innov Mod Eng Sci. 2019;5:1-6. http://ijtimes.com/papers/special_papers/ICMTCE13.pdf.

[10] Biologische Abgasreinigung - Biofilter (Biological waste gas purification - Biofilters). VDI 3477:2016-03. The Association of German Engineers; 2016. https://www.beuth.de/de/technische-regel/vdi3477/239551088.

[11] Bajpai P. Biological Odour Treatment. Cham Heidelberg New York Dordrecht London: Springer Briefs in Environmental Science. Springer International Publishing; 2014. 17-44. DOI: 10.1007/978-3-319-07539-6.

[12] Shareefdeen Z, Singh A. Biotechnology for Odour and Air Pollution Control. Berlin: Springer Science \& Business Media; 2005. 125-45. DOI: 10.1007/b138434.

[13] Lelicinska-Serafin K, Rolewicz-Kalinska A, Manczarski P. VOC removal performance of a joint process coupling biofiltration and membrane-filtration treating food industry waste gas. Int $\mathrm{J}$ Environ Res Public Health. 2019;16(17):1-4. DOI: 10.3390/ijerph16173009.

[14] Xi J, Saingam P, Gu F, Hu H. Effect of continuous ozone injection on performance and biomass accumulation of biofilters treating gaseous toluene. Appl Microbiol Biotechnol. 2014;98:9437-46. DOI: 10.1007/s00253-014-5888-z.

[15] Bohn H. Soil and compost filters of malodorant gases. J Air Pollut Control Assoc. 1975;25(9):953-5. DOI: 10.1080/00022470.1975.10468118.

[16] Kennes C, Thalasso F. Review: Waste gas biotreatment technology. J Chem Technol Biotechnol. 1998;72:303-19. DOI: 10.1002/(SICI)1097-4660(199808)72:4<303::AID-JCTB903>3.0.CO;2-Y.

[17] Detchanamurthy S, Gostomski P. Rev Environ Sci Biotechnol. 2012;11:231-41. DOI: 10.1007/s11157-012-9288-5.

[18] Burgess J, Parsons S, Stuetz R. Developments in odour control and waste gas treatment biotechnology: a review. Biotechnol Advances. 2001;19(1):35-63. DOI: 10.1016/S0734-9750(00)00058-6.

[19] ISO 10390:2005. Soil quality - Determination of pH. https://www.iso.org/standard/40879.html.

[20] Polish Standard PN-Z-15008-02:1993. Odpady komunalne stałe - Badania właściwości paliwowych Oznaczanie wilgotności całkowitej (Solid municipal wastes - Fuel properties tests - Determination of total humidity). https://sklep.pkn.pl/pn-z-15008-02-1993p.html?options=cart.

[21] Polish Standard PN-EN 15002:2015-07. Characterization of waste - Preparation of samples for analysis from the laboratory sample. https://sklep.pkn.pl/pn-en-15002-2015-07e.html.

[22] Polish Standard PN-Z-15011-2:1998. Kompost z odpadów komunalnych -- Oznaczanie: pH, zawartości substancji organicznej, węgla organicznego, azotu, fosforu i potasu (Municipal waste compost Determination of: $\mathrm{pH}$, organic matter content, organic carbon, nitrogen, phosphorus and potassium). https://sklep.pkn.pl/pn-z-15011-2-1998p.html. 